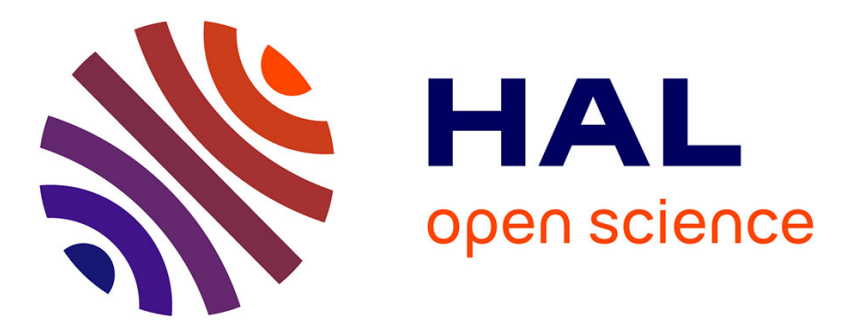

\title{
About one stable and three metastable eutectic microconstituents in the Fe-W-C system
}

\author{
A. Antoni-Zdziobek, J.Y. Shen, M. Durand-Charre
}

\section{To cite this version:}

A. Antoni-Zdziobek, J.Y. Shen, M. Durand-Charre. About one stable and three metastable eutectic microconstituents in the Fe-W-C system. International Journal of Refractory Metals and Hard Materials, 2007, 26 (4), pp.372-382. 10.1016/j.ijrmhm.2007.09.001 . hal-00345159

\section{HAL Id: hal-00345159 \\ https://hal.science/hal-00345159}

Submitted on 21 Apr 2020

HAL is a multi-disciplinary open access archive for the deposit and dissemination of scientific research documents, whether they are published or not. The documents may come from teaching and research institutions in France or abroad, or from public or private research centers.
L'archive ouverte pluridisciplinaire HAL, est destinée au dépôt et à la diffusion de documents scientifiques de niveau recherche, publiés ou non, émanant des établissements d'enseignement et de recherche français ou étrangers, des laboratoires publics ou privés. 


\title{
About one stable and three metastable eutectic microconstituents in the $\mathrm{Fe}-\mathrm{W}-\mathrm{C}$ system
}

\author{
A. Antoni-Zdziobek *, J.Y. Shen, M. Durand-Charre \\ SIMAP, INPGrenoble-CNRS-UJF, BP 75, F-38402 Saint-Martin d'Hères, France
}

Received 15 February 2007; accepted 6 September 2007

\begin{abstract}
The Fe-W-C system has been the subject of numerous investigations and the findings have led to quite different interpretations in the iron-rich corner, justifying the need for new experimental studies. In the present study, some 12 compositions are prepared using both the powder metallurgy technique and the casting of melted alloys. DTA experiments, long time annealing supplemented by the phase separation technique and controlled solidification experiments are carried out. The micrographs of the corresponding specimens reveal significant sedimentation of WC carbides, an observation which must be carefully taken into account in interpreting the micrographs. The liquid/solid equilibria between 1423 and $1543 \mathrm{~K}$ are investigated and the corresponding partial isothermal sections of the Fe-W-C system are compared to the calculated phase equilibria based on thermochemical models. Four ternary eutectic microconstituents $\gamma / \mathrm{M}_{6} \mathrm{C} /$ cementite, $\gamma / \mathrm{WC} /$ cementite, $\gamma / \mathrm{M}_{6} \mathrm{C} /$ graphite and $\gamma / \mathrm{WC} /$ graphite, are observed by experiments. The microstructures are characterised and the four eutectic temperatures are established both experimentally and by calculations. The experimental eutectic temperatures lie within a range of $10 \mathrm{~K}$ but well below the temperatures predicted by thermodynamic modelling and the calculated temperatures within a range of $20 \mathrm{~K}$. This explains why metastable microconstituents can so readily be formed.
\end{abstract}

Keywords: Fe-W-C system; Solid-liquid equilibria; Ternary eutectic; Electromagnetic phase separation

\section{Introduction}

The $\mathrm{Fe}-\mathrm{W}-\mathrm{C}$ system may be considered as the fundamental system for interpreting the structure of many commercial alloys such as high-speed and tool steels. The system has therefore been the subject of extensive investigations. Solid state equilibria have been studied by numerous authors [1-3] but little experimental works has been done on liquid/solid equilibria. In 1931, Takeda [4] published the first systematic experimental studies on the system. In 1968, Jellinghaus [5] experimentally determined the basic entire phase diagram. In 1978, Shevchuk et al. [6] provided information on phase equilibria involving the liquid phase. In 1985, Gabriel et al. [7] used a phase separation technique

\footnotetext{
${ }^{*}$ Corresponding author. Tel.: +33 476 826747; fax: +33 476826745 .

E-mail address: aantoni@ltpcm.inpg.fr (A. Antoni-Zdziobek).
}

to obtain new data concerning equilibria involving the liquid phase. In 1985, a compilation by Rivlin [8] underlined the differences between the findings of different authors. In 1997, Shtansky et al. [9] described the mechanism and kinetics of carbide transformation in $\mathrm{Fe}-\mathrm{W}-\mathrm{C}$ steels at $973 \mathrm{~K}$. More recent studies have focused on the decomposition of austenite in $\mathrm{Fe}-\mathrm{W}-\mathrm{C}$ steels [10-12].

The first diagrams based on calculations were proposed by Uhrenius [13] in 1980, based on some new experimental data from Åkesson [14]. This was followed in 1987, by a new thermodynamic evaluation of the system by Gustafson [15], again using the above-mentioned experimental results.

Nevertheless the liquid-solid equilibria in the iron-rich corner remain a point of controversy. The studies reported to date yield phase diagrams with major differences in the extent of the primary phase fields, and in particular, the primary $\mathrm{WC}$ carbide phase field. The main points of controversy concern the eutectic temperatures, gross 
compositions and the phases constituting the various ternary eutectic microstructures in the iron-rich field. Surprisingly, up to four eutectic microconstituents are reported, all of them involving austenite ( $\gamma$ phase) and two other solid phases: graphite, $\mathrm{WC}$, cementite $\left(\mathrm{Fe}_{3} \mathrm{C}\right)$ and $\eta$-carbide $\left(\mathrm{M}_{6} \mathrm{C}\right)$. The ternary eutectic temperatures are reported to lie within a range of $58 \mathrm{~K}$ (values are reported in Table 1). The ternary eutectic point liquid $\leftrightarrow \gamma \mathrm{WC}+$ graphite is considered to represent the stable state.

The WC, $\mathrm{MC}_{1-x}, \mathrm{M}_{6} \mathrm{C}, \mathrm{M}_{3} \mathrm{C}$ and $\mathrm{M}_{2} \mathrm{C}$ carbides have been reported to be microconstituents of liquid/solid equilibria. The $\mathrm{Fe}-\mathrm{W}-\mathrm{C}$ system shows similarities with the $\mathrm{Fe}-\mathrm{Mo}-\mathrm{C}$ system. The $\xi$ phase $\left(\mathrm{Fe}_{2}(\mathrm{Mo}, \mathrm{W}) \mathrm{C}\right)$ identified and studied by numerous authors $[2,10,16,17]$ is involved in liquid/solid equilibria in the $\mathrm{Fe}-\mathrm{Mo}-\mathrm{C}$ system and only in solid/solid equilibria [2] in the Fe-W-C system. Structural similarity with cementite has been recognized and the $\xi$ phase is therefore often referred to as molybdenum cementite. In 1992, Shen et al. [18] characterised the $\xi$ carbide in an $\mathrm{Fe}-13.4 \mathrm{~W}-3.1 \mathrm{C}$ (mass percent) alloy maintained for $2 \mathrm{~h}$ at $1333 \mathrm{~K}$. The morphology was not significantly changed in relation to the microstructure of the as-cast sample with primary WC blocky carbides observed alongside ternary eutectic $\mathrm{M}_{6} \mathrm{C}$ carbides $(\mathrm{Fe}-33 \mathrm{~W}-15 \mathrm{C}$ in at.\%) and $\mathrm{M}_{3} \mathrm{C}$. However, $\mathrm{M}_{3} \mathrm{C}(\mathrm{Fe}-0.4-3 \mathrm{~W}-23.5 \mathrm{C}$ in at.\%) and $\xi$ carbides $(\mathrm{Fe}-16.5 \mathrm{~W}-20 \mathrm{C}$ in at.\%) were identified in a small proportion.

The experimental procedure used in preparing the alloys plays an important role. The microstructures are quite different when obtained on as-cast specimens following solidification of a melt, or after long time annealing of sintered specimens. Shen et al. [18] characterised a ternary eutectic with $\gamma$, cementite and $\mathrm{M}_{6} \mathrm{C}$ and proposed an alternative metastable liquidus surface that was rather different from those found in the literature. The crystallisation paths were determined by quench interrupted solidification during thermal analysis [19] (QDTA). It was shown that the eutectic microconstituent is transformed under $1273 \mathrm{~K}, \mathrm{M}_{6} \mathrm{C}$

Table 1

Eutectic reactions mentioned in the literature

\begin{tabular}{lccrr}
\hline Microconstituents & \multicolumn{2}{l}{ Eutectic reactions } & \multirow{2}{*}{ Ref. } \\
\cline { 2 - 3 } & \multicolumn{2}{l}{ Composition (mass $\%)$} & \\
\cline { 2 - 3 } & $\mathrm{W}$ & $\mathrm{C}$ & & \\
\hline Experimental & & & & \\
$\gamma / \mathrm{WC} /$ graphite (stable) & 4.9 & 4.2 & 1416 & {$[14]$} \\
$\gamma / \mathrm{WC} /$ cementite (metastable) & 15 & 3.6 & 1358 & {$[5]$} \\
$\gamma / \mathrm{WC} /$ cementite (metastable) & & & 1408 & {$[14]$} \\
$\gamma / \mathrm{M}_{6}$ C/graphite & & & 1358 & {$[14]$} \\
$\gamma / \mathrm{M}_{6}$ C/cementite (metastable) & 17 & 3.7 & 1358 & {$[14]$} \\
$\gamma / \mathrm{M}_{6} \mathrm{C} /$ cementite (metastable) & 20 & 4.2 & 1323 & {$[6]$} \\
$\gamma / \mathrm{M}_{6} \mathrm{C} /$ cementite & 19.8 & 3.9 & 1358 & {$[18]$} \\
Calculated & & & & \\
$\gamma / \mathrm{WC} /$ graphite & 5.1 & 4.2 & 1416 & {$[13]$} \\
$\gamma / \mathrm{M}_{6}$ C/cementite (metastable) & 12.6 & 4.2 & 1394 & {$[13]$} \\
$\gamma / \mathrm{M}_{6}$ C/graphite (metastable) & 13.0 & 4.1 & 1397 & {$[13]$} \\
$\gamma / \mathrm{WC} /$ graphite & 4.9 & 4.2 & 1413 & {$[15]$} \\
\hline
\end{tabular}

disappears and WC carbides grow with a plate-like morphology.

This ternary eutectic structure with $\gamma$, cementite and $\mathrm{M}_{6} \mathrm{C}$ was observed in commercial alloys containing $\mathrm{W}$, such as tool steels or cast irons. However, these alloys contain many additional elements that may modify the eutectic structure.

The aim of the present study is to clarify these discrepancies. It focuses mainly on phase equilibria involving the liquid phase and in particular on reactions leading to the various ternary eutectics.

\section{Preparation of alloys and experimental procedures}

\subsection{The electromagnetic phase separation technique}

Equilibria involving a liquid phase were investigated using the technique of electromagnetic phase separation as described by Allibert et al. [20,21]. The starting materials are placed in an alumina crucible encased in a graphite container and heated in a medium frequency induction furnace $(10 \mathrm{kHz})$, under helium atmosphere. The temperature is measured by an alumina-sheathed $\mathrm{Pt}-30 \% \mathrm{Rh} / \mathrm{Pt}-6 \% \mathrm{Rh}$ thermocouple immersed in the melt. The thermocouple is calibrated against the Ni melting point. Induction currents heat the sample and create inside electromagnetic forces related to the electrical power supplied in the coil. The specimen temperature increases up to the melting range. Electromagnetic forces result in a stirring movement of the liquid metal. Solid particles present in the stirred liquid bath are dragged by the movement of the liquid and then trapped near the walls of the crucible. The temperature is then stabilized at the chosen value. After isothermal treatment lasting several hours, an equilibrium state is reached. When the electric power is cut off in the coil, the quick cooling of the specimen results in the high-temperature configuration freezed in. The cooling rate is estimated at about $900 \mathrm{~K} / \mathrm{min}$ above $1273 \mathrm{~K}$. The chemical analysis of spatially separated phases makes it possible to arrive at the composition of the ex-liquid in the upper portion of the specimen and of one or two solid phases in equilibrium at the studied temperature.

Nine alloy compositions were prepared by melting compacted powders of $\mathrm{Fe}, \mathrm{WC}$ and $\mathrm{C}$ and a proportion of electrolytic iron to facilitate induction melting. $150 \mathrm{~g}$ ingots were produced for each composition (compositions of the raw materials and the alloys are presented respectively in Tables 2 and 3). The following procedure was carried out:

- Heating at around $873 \mathrm{~K}$ for $2 \mathrm{~h}$.

- Heating in $\mathrm{He}$ atmosphere up to $1800 \mathrm{~K}$ for about $15 \mathrm{~min}$ to ensure the rapid dissolution of the most refractory elements into the molten iron.

- Lowering and maintaining temperature for $3 \mathrm{~h}$ at the chosen value of between 1473 and $1543 \mathrm{~K}$.

- Quenching. 
Table 2

Compositions of raw materials used in the preparation of investigated alloys

\begin{tabular}{ll}
\hline Material & Impurity contents in mass percent \\
\hline Electrolytic iron (Alfa Aesar) & $\% \mathrm{Fe}>99.97$ \\
Graphite powder (Cancarb) & $\% \mathrm{C}>99.5$ \\
Iron powder (Eurotungstene, $5.5 \mu \mathrm{m})$ & $\% \mathrm{Fe}>99.5,0.2 \% \mathrm{O}$ \\
Tungsten powder & $\% \mathrm{~W}>99.92,0.02 \% \mathrm{O}$ \\
$\quad$ (Eurotungstene, $4.5 \mu \mathrm{m})$ & \\
WC powder (Eurotungstene, $5 \mu \mathrm{m})$ & $0.025 \% \mathrm{O}$ \\
\hline
\end{tabular}

Table 3

Composition and designation of alloys used in electromagnetic phase separation experiments

\begin{tabular}{llrl}
\hline$T(\mathrm{~K})$ & Alloy No. & \multicolumn{2}{c}{ Composition $(\mathrm{mass} \%)$} \\
\cline { 3 - 4 } & & $\mathrm{W}$ & $\mathrm{C}$ \\
\hline 1423 & 1 & 5.01 & 4.00 \\
& 2 & 20.00 & 3.50 \\
1473 & 3.1 & 7.04 & 3.23 \\
& 3.2 & 6.02 & 2.71 \\
& 4 & 10.00 & 3.00 \\
& 5 & 20.00 & 4.14 \\
& 6 & 8.00 & 5.00 \\
& 7 & 20.00 & 3.50 \\
1543 & 8 & 20.00 & 2.51 \\
\hline
\end{tabular}

Alloy 2 was duplicated with alloy 7 in order to explore two annealing temperatures.

Polished vertical sections of the specimens were then investigated. In each of the eight experiments, the solid phases separate efficiently from the liquid. The distribution of the phases in areas including the solid/liquid boundary is shown in Figs. 1a and 1b. The alloys are rapidly solidified. Consequently, the area corresponding to the ex-liquid is characterized by a fine microstructure. The arrows in Fig. $1 \mathrm{~b}$ indicate a boundary limiting a liquid area. The coarse solid phases are located below this boundary. One solid phase is detected in samples 3.1 and 3.2 (namely $\gamma$ ) and in sample 5 (WC). Two solid phases are detected in samples 2,7 and 8 which are $\mathrm{WC}+\gamma$ in samples 2 and 7 and $\mathrm{M}_{6} \mathrm{C}+\gamma$ in sample 8 . Both W-rich coarse carbides appear with a bright contrast. The microanalysis of the treated samples showed a good homogeneity of the solid phases, indicating that thermodynamic equilibrium had been reached. Composition of the solid particles was analysed by electron microprobe analysis. The overall composition of the ex-liquid phase separated by the electromagnetic process was determined by chemical analysis of a specimen sampled in the quenched liquid area. Tungsten and iron were analysed by the Inductively Coupled Plasma (ICP) technique and carbon by the combustion method.

\subsection{DTA experiments}

The investigations performed by Shen et al. [18] were supplemented by the examination of three more composi-

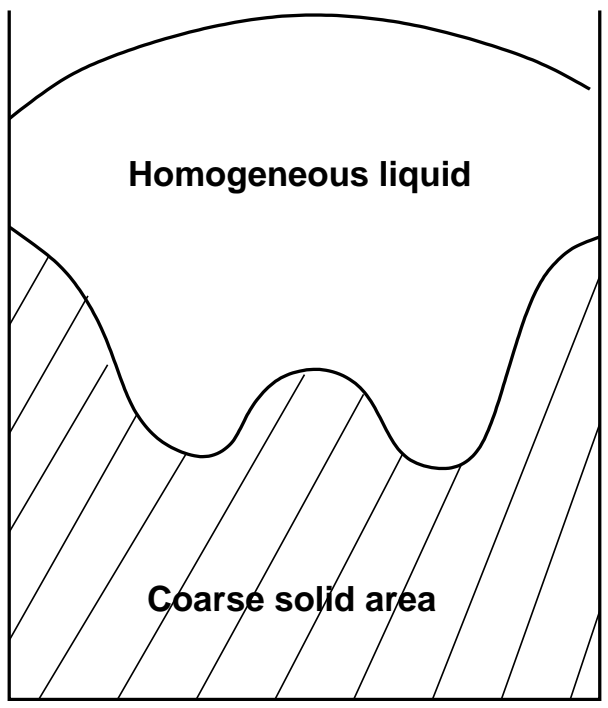

Fig. 1a. Schematic drawing of the arrangement of microstructures in alloys prepared by electromagnetic phase separation technique. The localization of the separated solid grains and the shape of the solid/liquid boundary are related to the size and to the number of circulating stream loops. At working temperature, solid particules present in the stirred liquid are dragged by the circulating stream lines up to regions of low velocity. Then they are trapped by surface reaction with the wall crucible where they coalesce with the particules previously trapped.

tions similar to the eutectic composition: alloy $\mathrm{A}(\mathrm{Fe}-$ $19.8 \mathrm{~W}-3.1 \mathrm{C}$ in mass percent), alloy $\mathrm{B}$ (Fe-16W-3.98C) and alloy $\mathrm{C}(\mathrm{Fe}-12.6 \mathrm{~W}-3.96 \mathrm{C})$. In all, seven compositions were investigated (compositions of the alloys are presented in Table 4). Raw materials used were $\mathrm{Fe}, \mathrm{W}$ and $\mathrm{C}$ powders (compositions of the initial materials presented in Table 2). Ingots of about $100 \mathrm{~g}$ of presintered pellets were melted in a cold crucible inductive furnace under argon atmosphere and cast in a water cooled mold. Settling of heavy carbides is avoided by this process and specimens display a fine, homogeneous distribution of phases, suitable for DTA experiments.

Specimens were cut into two parts. One was used for the chemical analysis of carbon by combustion methods, while the other was machined into small cylinders $(8 \mathrm{~mm}$ long, $5 \mathrm{~mm}$ in diameter) for DTA experiments. In a DTA furnace, heating was carried out under argon at a rate of $300 \mathrm{~K} / \mathrm{h}$ up to a temperature of $1643 \mathrm{~K}$ for alloy $\mathrm{A}$, $1583 \mathrm{~K}$ for alloy $\mathrm{B}$ and $1523 \mathrm{~K}$ for alloy C. Melting was ensured by maintaining the alloys at these temperatures for $3 \mathrm{~min}$ before slow cooling at a rate of 120 or $300 \mathrm{~K} / \mathrm{h}$.

In the solidification range of temperatures, DTA thermograms exhibit several peaks. The high temperature peak is poorly defined and cannot be attributed to a well-defined reaction since the primary phases probably form with severe supercooling. However at the end of the solidification period a well-defined peak is detected, enabling the invariant reactions to be determined.

The samples produced by both procedures were then observed by optical micrography and scanning electron microscopy (SEM), and characterised by X-ray diffraction 

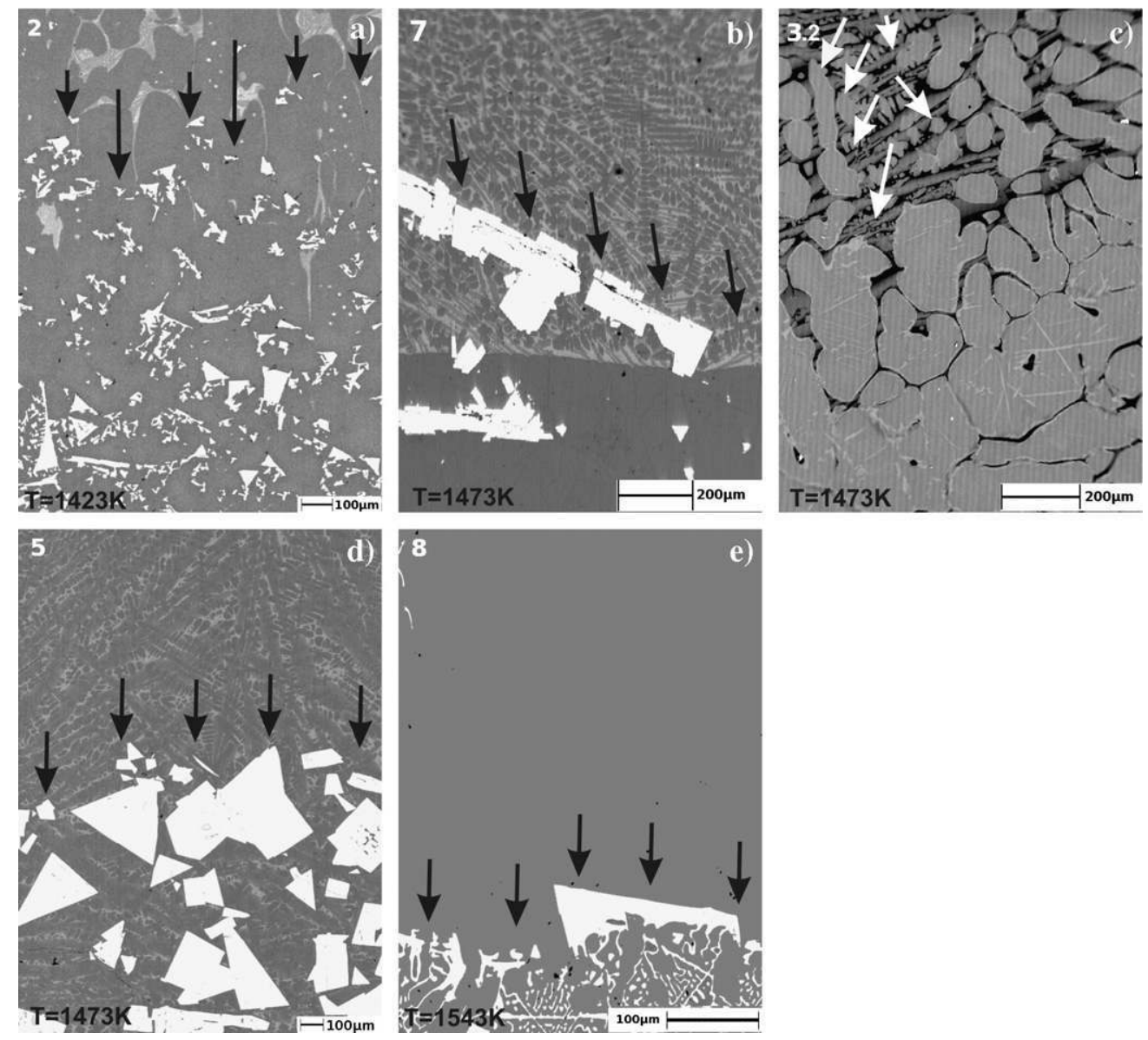

Fig. 1b. Scanning electron microscope images of vertical section of alloys prepared by electromagnetic phase separation technique and maintained for $3 \mathrm{~h}$ before quenching in areas including the solid/liquid boundary (located by arrows). 2 at $1423 \mathrm{~K} ; 3.2,5$ and 7 at $1473 \mathrm{~K} ; 8$ at $1543 \mathrm{~K}$. All compositions are given in mass percent. (a) Microstructure of sample $2(\mathrm{Fe}-20 \mathrm{~W}-3.5 \mathrm{C})$ in the $\mathrm{L}+\mathrm{WC}+\gamma$ three phase field. The ex-liquid phase is located in the upper part of the sample. (b) Microstructure of sample 7 (Fe-20W-3.5C) in the $\mathrm{L}+\mathrm{WC}+\gamma$ three phase field. Note the irregular aspect of the WC carbides. (c) Microstructure of sample $3.2(\mathrm{Fe}-6.02 \mathrm{~W}-2.71 \mathrm{C}$ ) showing separation between liquid and solid $\gamma$ now partly bainite. (d) Microstructure of sample 5 (Fe$20 \mathrm{~W}-4.14 \mathrm{C}$ ) with coarse faceted angular WC carbides. (e) Microstructure of sample 8 (Fe-20W-2.51C) with $\mathrm{M}_{6} \mathrm{C}$ carbides in the lower part and $\gamma$ phase.

Table 4

Composition and designation of alloys used in DTA experiments

\begin{tabular}{lll}
\hline Alloy No. & \multicolumn{2}{l}{ Composition $\left(\operatorname{mass}^{\circ} \%\right)$} \\
\cline { 2 - 3 } & $\mathrm{W}$ & $\mathrm{C}$ \\
\hline A (This work) & 19.80 & 3.10 \\
B (This work) & 16.00 & 3.98 \\
C (This work) & 12.60 & 3.96 \\
D [18] & 30.80 & 3.40 \\
E [18] & 5.60 & 2.30 \\
F [18] & 17.80 & 2.00 \\
G [18] & 13.40 & 3.10 \\
\hline
\end{tabular}

and electron microprobe analysis (EPMA) at $15 \mathrm{kV}$ using pure iron and WC standards.

\section{Results and discussion}

Thermo-Calc software [22] (r-version) and the TCFE5 database [23] were used to calculate the phase diagrams. This database is based on the thermodynamic description of the $\mathrm{Fe}-\mathrm{W}-\mathrm{C}$ system by Gustafson [15] and on a new description of the cubic WC phase by Jonsson [24].

\subsection{Determination of solidlliquid equilibria}

The composition of the phases in equilibria at the three investigated temperatures is reported in Table 5. The corresponding partial isothermal sections at 1423, 1473 and $1543 \mathrm{~K}$ are plotted in Figs. 2-4. The corresponding tie-lines are calculated and compared to the experimental ones.

\subsubsection{Section at $1423 \mathrm{~K}$}

The results shown in Fig. 2 are consistent with the calculated isothermal section. However, the $\mathrm{W}$ content of the liquid in the liq./WC/ $\gamma$ equilibrium is found to be higher than in the calculations (point $\mathrm{m} 1$ ). The experimental level of $\mathrm{C}$ in the liq./ $\gamma$ equilibrium is also higher in the liquid phase.

\subsubsection{Section at $1473 \mathrm{~K}$}

The five equilibria determined at this temperature are reported in Fig. 3 on the calculated isothermal section. Concerning the three-phase field liq./WC/ $\gamma$ the experimental point $\mathrm{m} 2$ is shifted to a higher $\mathrm{W}$ content than the cal- 
Table 5

Comparison between experimental and calculated tie-lines in the $\mathrm{Fe}-\mathrm{W}-\mathrm{C}$ system

\begin{tabular}{|c|c|c|c|c|c|c|c|c|c|c|c|c|c|c|}
\hline \multirow[t]{3}{*}{$T(\mathrm{~K})$} & \multirow[t]{3}{*}{ No. } & \multirow{3}{*}{$\begin{array}{l}\text { Phases } \\
\text { P1/P2/P3 }\end{array}$} & \multicolumn{4}{|c|}{ Phase $1\left(\operatorname{mass}^{0} \%\right)$} & \multicolumn{4}{|c|}{ Phase 2 (mass $\%)$} & \multicolumn{4}{|c|}{ Phase $3\left(\operatorname{mass}^{0} \%\right)^{\mathrm{c}}$} \\
\hline & & & \multicolumn{2}{|l|}{$\mathrm{W}$} & \multicolumn{2}{|l|}{$\mathrm{C}$} & \multicolumn{2}{|l|}{$\mathrm{W}$} & \multicolumn{2}{|l|}{$\mathrm{C}$} & \multicolumn{2}{|l|}{ W } & \multicolumn{2}{|l|}{$\mathrm{C}$} \\
\hline & & & Exp. & Calc. & Exp. & Calc. & Exp. & Calc. & Exp. & Calc. & Exp. & Calc. & Exp. & Calc. \\
\hline & 2 & Liq. $/ \gamma / \mathrm{WC}$ & 9.80 & 6.16 & 4.04 & 4.07 & 2.37 & 2.47 & 1.59 & 1.93 & 90.39 & 93.87 & 6.61 & 6.13 \\
\hline \multirow[t]{4}{*}{1473} & 3.1 & Liq. $/ \gamma$ & 7.65 & 7.87 & 3.78 & 3.57 & 3.12 & 3.07 & 1.38 & 1.63 & & & & \\
\hline & 3.2 & Liq. $/ \gamma$ & 8.00 & 9.22 & 3.68 & 3.50 & 3.25 & 3.69 & 1.31 & 1.60 & & & & \\
\hline & $6^{\mathrm{a}}$ & Liq./graphite & 7.80 & 7.40 & 4.33 & 4.32 & & 0 & & 100 & & 93.87 & & 6.13 \\
\hline & 7 & Liq. $/ \gamma / \mathrm{WC}$ & 11.90 & 9.94 & 3.55 & 3.47 & 4.78 & 4.04 & 1.55 & 1.58 & 92.74 & 93.87 & 6.25 & 6.13 \\
\hline 1543 & $8^{\mathrm{b}}$ & Liq. $/ \gamma / \mathrm{M}_{6} \mathrm{C}$ & 22.00 & 19.77 & 2.73 & 2.49 & 9.36 & & 1.45 & & 68.72 & 93.87 & 2.10 & 6.13 \\
\hline
\end{tabular}

The values were established by analysis of the three elements Fe, W and $\mathrm{C}$. Fe content, not indicated here, is the complement to $100 \%$.

a According to the calculations, WC carbide is also present in these alloys.

b According to the calculations, this alloy is in the two-phase field liq./WC

${ }^{c}$ To be noticed that a small amount of iron-between $1 \%$ and $3 \%$ - is detected in WC (see Section 3.2).

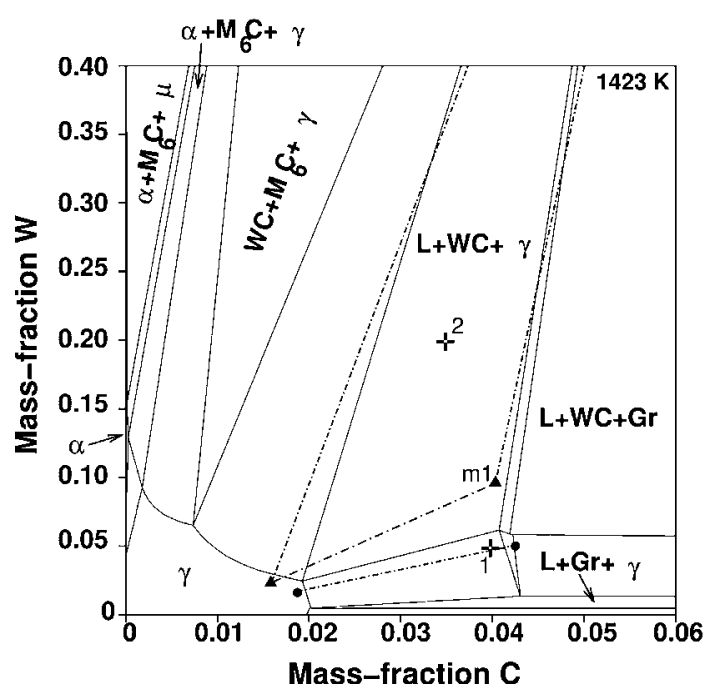

Fig. 2. Comparison of experimental data for samples 1 and 2 annealed at $1423 \mathrm{~K}$ (dot-dash lines) with the corresponding calculated isothermal section of the $\mathrm{Fe}-\mathrm{W}-\mathrm{C}$ system (solid lines). The compositions are presented in Table 5. Symbols 1 and 2(+): gross compositions of alloys 1 and 2. Symbol $\mathrm{ml}$ : experimental composition of the liquid phase at $1423 \mathrm{~K}$ of alloy 2 in Table 5. It should be noted that the shift between the nominal composition WC and the analysed values induced a slight tilt of the tie-lines.

culated point. This discrepancy does not seem to be due to experimental error because the same trend is observed at $1423 \mathrm{~K}$. The results demonstrate the shrinkage of the three-phase field liq./WC/ $\gamma$ and the expansion of the liquid region when the temperature increases from 1423 to $1473 \mathrm{~K}$. The experimental liq./WC and liq./graphite tielines are in good agreement with calculations.

\subsubsection{Section at $1543 \mathrm{~K}$}

Only one composition (8) was investigated at this temperature (Fig. 4). The liq./ $\mathrm{M}_{6} \mathrm{C} / \gamma$ tie-triangle was determined experimentally. For this composition, calculations

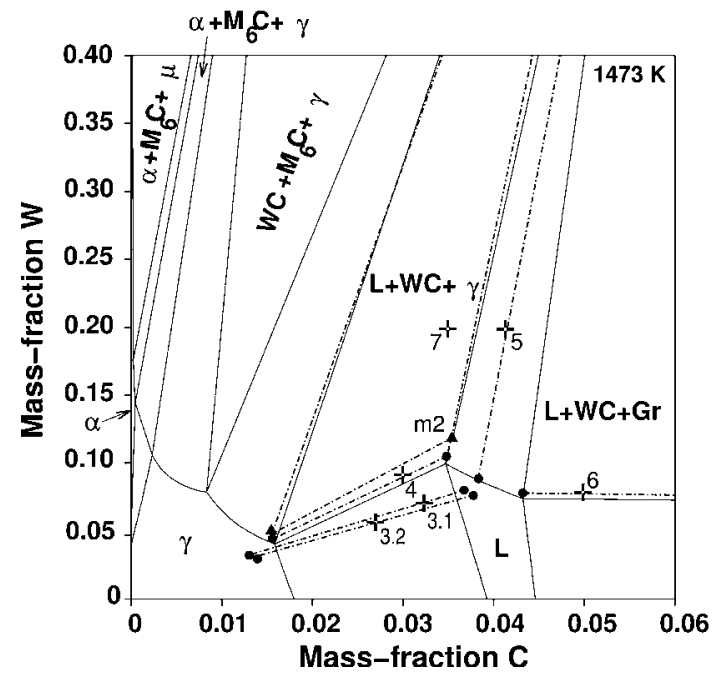

Fig. 3. Comparison of experimental data for samples 3.1, 3.2, 4 and 7 annealed at $1473 \mathrm{~K}$ (dot-dash lines) with the corresponding calculated isothermal section of the $\mathrm{Fe}-\mathrm{W}-\mathrm{C}$ system (solid lines). The compositions are presented in Table 5. Symbols 3.1, 3.2, 4, 5, 6 and 7(+): gross compositions of alloys 3.1-7. Symbol m2: experimental composition of the liquid phase at $1473 \mathrm{~K}$ of alloy 7 in Table 5 .

predict only a two-phase equilibrium liq./WC. However, the compositions analysed for the coexisting phases are in good agreement with the experimental results reported by Akkesson [25] for the liq./ $\mathrm{M}_{6} \mathrm{C} / \gamma$ equilibria at $1593 \mathrm{~K}$ and both sets of results confirm the extension of the above-mentioned three-phase field to a lower range of tungsten compositions.

\subsubsection{Positions of the univariant lines}

Each composition of the liquid at 1423, 1473 and $1543 \mathrm{~K}$ in equilibrium with two solid phases corresponds to a point on a monovariant line. The univariant lines liq./WC $+\gamma$, liq. $/ \mathrm{M}_{6} \mathrm{C}+\mathrm{WC}$ and liq. $/ \mathrm{M}_{6} \mathrm{C}+\gamma$ line are plotted in Fig. 5-according to our results - as hatched lines and 


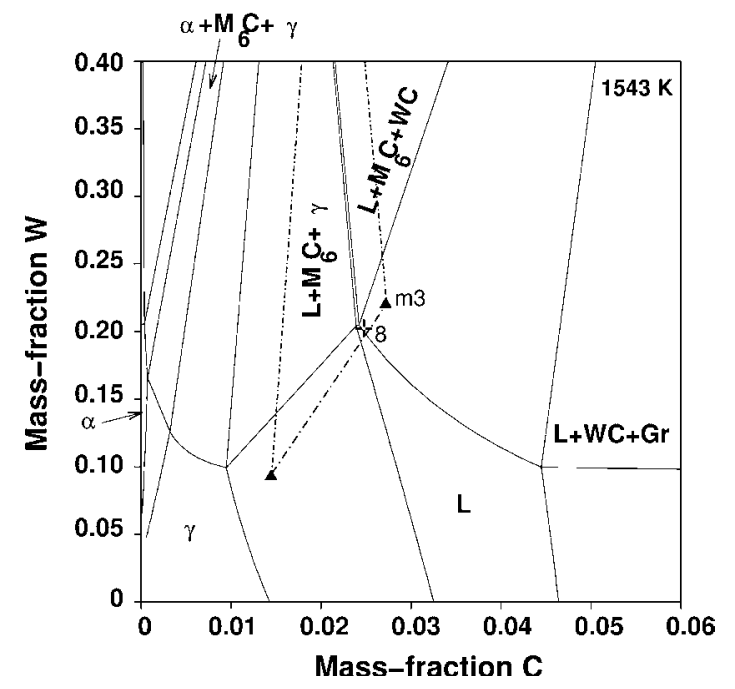

Fig. 4. Comparison of experimental data for sample 8 annealed at $1543 \mathrm{~K}$ (dot-dash lines) with the corresponding calculated isothermal section of the $\mathrm{Fe}-\mathrm{W}-\mathrm{C}$ system (solid lines). The compositions are presented in Table 5. Symbol 8(+): gross composition of alloy 8 . Symbol m3: experimental composition of the liquid phase at $1543 \mathrm{~K}$ of alloy 8 in Table 5.

compared with the calculated (solid) lines. Point E corresponds to the ternary eutectic $\mathrm{M}_{6} \mathrm{C} /$ cementite $/ \gamma$ discussed in the next part. The monovariant line liq./WC $+\gamma$ appears to lie at a higher $\mathrm{W}$ content than the calculated line. The positions of the experimental and calculated monovariant lines differ by about 4 mass $\% \mathrm{~W}$. However, the present results are in rather good agreement with the experimental results from Akesson [14] for the liq./M $\mathrm{M}_{6} \mathrm{C}+\gamma$ monovariant line and from Gabriel [7] for the liq./ $\mathrm{M}_{6} \mathrm{C}+\mathrm{WC}$ monovariant line. The liq./WC $+\gamma$ line should intercept the liq./ $\mathrm{M}_{6} \mathrm{C}+\gamma$ and the liq./ $\mathrm{M}_{6} \mathrm{C}+\mathrm{WC}$ lines at a temperature close to $1543 \mathrm{~K}$. Thus the $\mathrm{U}$ peritectic point for the equilib-

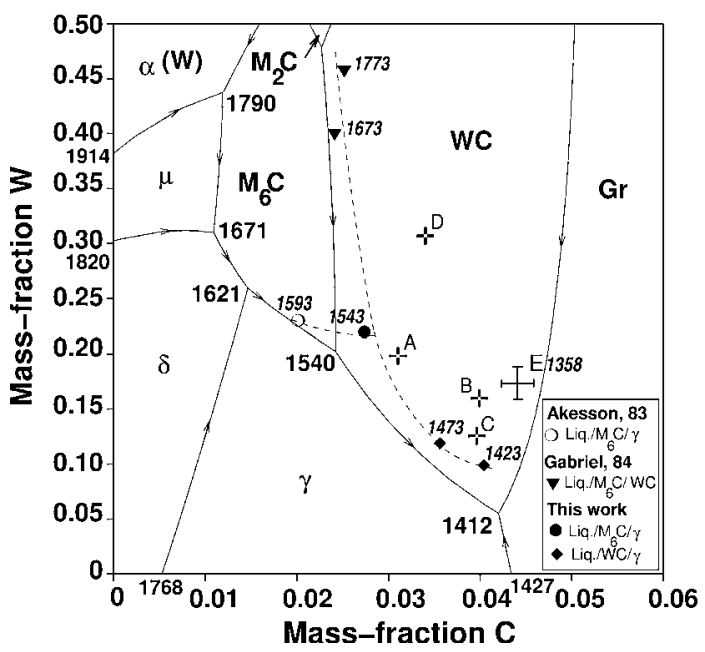

Fig. 5. Experimental data from literature $[7,14]$ and own results experimentally obtained for the monovariant lines liq./ $\mathrm{M}_{6} \mathrm{C}+\gamma$ and liq./ $\mathrm{WC}+\gamma$ (hatched lines) compared with calculated monovariant lines. Point E marks the position of the experimentally established (metastable) ternary eutectic liq. $\leftrightarrow \gamma+\mathrm{M}_{6} \mathrm{C}+$ cementite. rium liq. $+\mathrm{M}_{6} \mathrm{C} / \mathrm{WC}+\gamma$ lies at about 3 mass $\% \mathrm{C}$ and 20 mass $\% \mathrm{~W}$ and corresponds to a temperature close to $1543 \mathrm{~K}$. Our experimental results enlarge the $\mathrm{M}_{6} \mathrm{C}$ primary field and place the monovariant line liq. $/ \mathrm{M}_{6} \mathrm{C}+\mathrm{WC}$ at about 2.3 mass $\%$ C. The WC primary field should be slightly less extensive.

\subsection{Solidification paths}

Solidification paths are usually established by DTA and QDTA experiments but in the case of the Fe-W-C system, this is not easy because for the seven compositions investigated (Table 4) the crystallisation paths were dependent on the solidification rate. Also the link between the DTA-determined temperatures and the micrographs is not direct. Observation of all the specimens reveals a change in microstructure between the top and bottom of the vertical section of the sample. A high proportion of settled precipitated WC carbides is observed at the bottom of the specimen. The settling effect is enhanced at low solidification rates. In addition the microconstituents detected along the section are different and seem to be related to overall variations in $\mathrm{W}$ concentration.

Fig. 6 shows a selection of typical micrographs.

\subsubsection{Alloy $A(\mathrm{Fe}-19.8 \mathrm{~W}-3.1 \mathrm{C})$}

At least four phases are detected: $\gamma$, cementite, $\mathbf{M}_{6} \mathrm{C}$ and WC. These latter carbides formed first and then sink to the bottom of the ingot on account of their higher density. Their facetted shapes, either pyramidal or cubic, point to free growth in the liquid. The next steps in crystallisation process are more difficult to determine since several phases formed with a primary phase morphology: $\gamma$ austenite dendrites and cementite needles. These phases probably grow in the melt since their development is never stopped. The occurrence of several primary structures may be explained by a difficult nucleation of the phases. It should be noted that a facetted morphology, as in the case of the WC particles, is usually related to high supercooling. Thus substantial chemical supersaturation is necessary for WC nucleation in the liquid, otherwise metastable phases will tend to take place. The WC blocky carbides with angular shapes illustrate the morphology of primary WC carbides without there being any physical connection with the ternary eutectic. Two eutectic microconstituents can be distinguished above the settled WC carbides: $\gamma / \mathrm{M}_{6} \mathrm{C} /$ cementite in a substantial proportion and $\gamma / \mathrm{WC} /$ cementite.

\subsubsection{Alloy $\mathrm{D}(\mathrm{Fe}-30.8 \mathrm{~W}-3.4 \mathrm{C})$}

This alloy, previously investigated by Shen et al. [18], presents a similar microstructure and also contains primary WC carbides as a sediment at the bottom of the ingot. In the upper part, both primary austenite dendrites and primary cementite needles are observed. The matrix is formed by a very fine eutectic microconstituent, the three phases being identified as $\gamma, \mathrm{M}_{6} \mathrm{C}$ and cementite. 

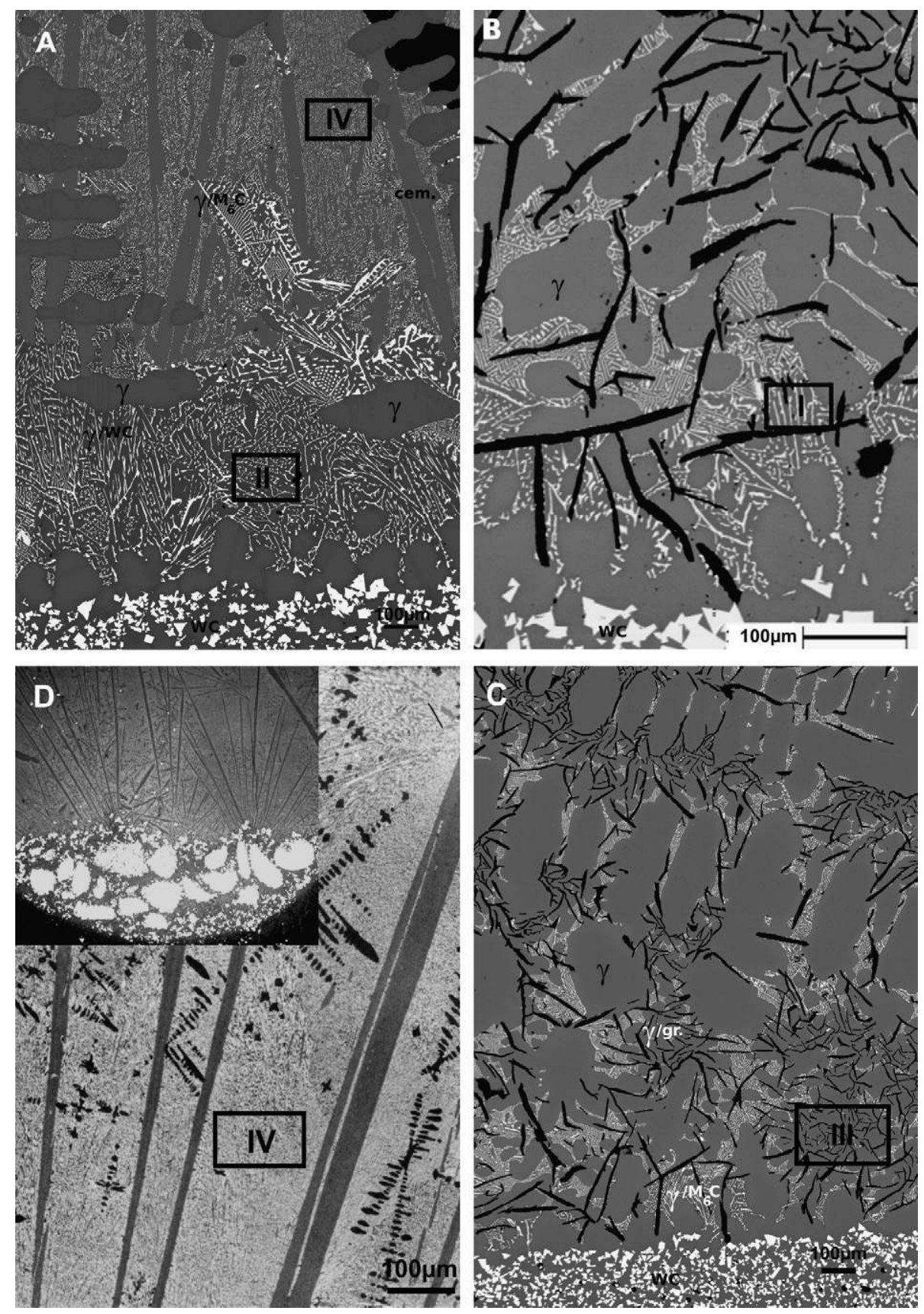

Fig. 6. Scanning electron microscope images of vertical section of DTA specimens: (A) Fe-19.8W-3.1C cooled at 2 K/min from 1643 K; (B) Fe-16W$3.98 \mathrm{C}$ cooled at $2 \mathrm{~K} / \mathrm{min}$ from $1583 \mathrm{~K}$, (C) Fe-12.6W-3.96C cooled at $5 \mathrm{~K} / \mathrm{min}$ from $1523 \mathrm{~K}$. (D) Fe-30.8W-3.4C cooled at $5 \mathrm{~K} / \mathrm{min}$ [18]. All compositions are given in mass percent. The areas labelled I-IV correspond to the micrographs presented in Fig. 8; In part D, an insert shows the bottom of the ingot in which the carbides are observed as a sediment like in part A, B and C.

\subsubsection{Alloys $B(F e-16 W-3.98 C)$ and $C(F e-12.6 W-3.96 C)$}

Again, coarse faceted tungsten WC carbides settled to the bottom of the ingot and two primary phases appear above, $\gamma$ austenite dendrites and large graphite flakes. In the interdendritic regions, three phases are observed $\gamma$, fine graphite flakes and $\mathrm{M}_{6} \mathrm{C}$ carbides, under the morphology of two eutectic microconstituents, one binary $\gamma / \mathrm{M}_{6} \mathrm{C}$, and the other ternary $\gamma / \mathrm{M}_{6} \mathrm{C} /$ graphite. Although cementite might be expected for such compositions $[2,13]$, it was not found.
Carbide analyses are presented in Table 6. Cementite and $\mathrm{M}_{6} \mathrm{C}$ carbides are stoichiometric with respect to $\mathrm{C}$. In cementite, the tungsten content is about $2-3$ at. $\% \mathrm{~W}$. In $\mathrm{M}_{6} \mathrm{C}$ carbides, the tungsten content is limited to 35 at.\% W. This proportion $\left(\mathrm{Fe}_{3.5} \mathrm{~W}_{2.5} \mathrm{C}\right)$ corresponds exactly to the experimental values proposed by Pollock [1] even if a larger extent is proposed by Holleck [26] up to $\mathrm{Fe}_{3-x} \mathrm{~W}_{3+x} \mathrm{C}$ in solid state equilibria. The $\mathrm{WC}$ carbides are stoichiometric with respect of $\mathrm{C}$. They are also usually expected to be perfectly stoichiometric with respect to $\mathrm{W}$ 
Table 6

Composition of different carbides in slowly cooled DTA samples determined by EPMA

\begin{tabular}{llccc}
\hline Alloy & Phase & \multicolumn{2}{c}{ Composition (at.\%) } \\
\cline { 3 - 5 } & & $\mathrm{W}$ & $\mathrm{C}$ & $\mathrm{Fe}$ \\
\hline $\mathrm{A}$ & Cementite & $2.06-2.82$ & $22.24-23.14$ & $74.06-77.24$ \\
$\mathrm{~A}, \mathrm{C}$ & $\mathrm{M}_{6} \mathrm{C}\left(\mathrm{Fe}_{3.5} \mathrm{~W}_{2.5} \mathrm{C}\right)$ & $35.88-36.53$ & $14.46-15.04$ & $48.43-49.56$ \\
& $\mathrm{WC}$ & $48.58-50.72$ & $47.03-50.09$ & $0.20-3.66$ \\
\hline
\end{tabular}

but our analysis found a low iron solubility of about $0.2-3$ at.\% Fe. This fact has already been observed by Uhrenius [13]. Usually iron is considered to have negligible solubility in WC [11]. In an earlier investigation concerning an alloy containing 4\% $\mathrm{Cr}$ (Fig. 7), Shen et al. [18] discriminated two classes of tungsten carbides, one with nearly no iron in $\mathrm{WC}\left(\mathrm{Fe}_{0.01} \mathrm{~W}_{0.99} \mathrm{C}_{0.99} \mathrm{Cr}_{0.01}\right.$ named $\left.\mathrm{WC}\right)$ and the other with a low iron content $\left(\mathrm{Fe}_{0.17} \mathrm{~W}_{0.86} \mathrm{C}_{0.93} \mathrm{Cr}_{0.04}\right.$ named $\mathrm{WC}_{\mathrm{Fe}}$ ). The authors pointed out a relationship between the composition and morphology of carbides. As presented in Fig. 7, the WC carbides of about $40 \mu \mathrm{m}$ exhibit a geometric facetted shape with an even surface. A compact zone is observed on the border of the carbides. The $\mathrm{WC}_{\mathrm{Fe}}$ carbides, though facetted, appear with a mottled surface as if containing tiny inclusions.

An interpretation is proposed assuming that $\mathrm{WC}_{\mathrm{Fe}}$ carbides are formed during a solid state transformation. It is

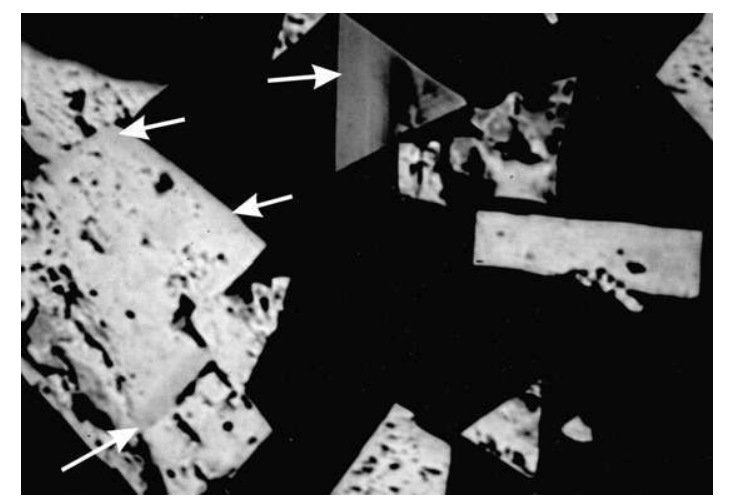

Fig. 7. Scanning electron microscope image of a $\mathrm{Fe}-20 \mathrm{~W}-4 \mathrm{C}-4 \mathrm{Cr}$ (mass percent) showing two kinds of WC carbides: pyramidal (grey) or cubic clear grey) shape corresponding to different compositions. assumed that the carbides which form first from the liquid are $\mathrm{MC}_{1-x}$ due possibly to an easier nucleation than WC carbides. On subsequent cooling, this metastable carbide undergoes an internal transformation into WC. Then tiny iron islands are embedded in $\mathrm{WC}_{\mathrm{Fe}}$ carbides during cooling. This could explain why iron analysis lies in a range between $1 \%$ and $3 \%$.

3.2.3.1. The ternary eutectic. Four eutectic microconstituents were identified in our present study, depending on the solidification rate and the initial compositions which can be classified into four groups (see Table 7). Their microstructure is presented in Fig. 8. Each micrograph is representative of the characteristic morphology for this ternary eutectic. Correlations can be made with the calculated respective proportions of the phases.

High $W$ low C: $\gamma /$ WClcementite (II Fig. 8). It may be observed that WC carbides, though facetted, are not as massive as the primary carbides observed at the bottom of the ingot.

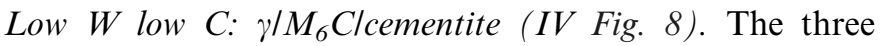
phases have a closely interlinked morphology, clearly indicating coupled growth. A similar morphology was found for the ternary eutectic in the FeMoC system [16]. The structure is fine enough to allow the global composition to be checked with the microprobe analyser. The corresponding invariant point is located at $4.2 \mathrm{C}( \pm 0.2 \%)$ and $18.6 \mathrm{~W}( \pm 1.3 \%)$. DTA measurements exhibit a thermal arrest at $1358 \mathrm{~K}$ which can be ascribed to this eutectic reaction. The $\gamma / \mathrm{M}_{6} \mathrm{C} / \mathrm{cementite}$ microconstituent is found to systematically occur in the as-solidified alloys. The measurements of the corresponding eutectic temperature of $1358 \mathrm{~K}$ are perfectly reproducible.

High $W$ high C: $\gamma / W C /$ graphite (I Fig. 8). In DTA specimen B, two different eutectic structure were observed close to one another with both austenite and graphite. In the area located on the left of the micrograph I (dark band) the third phase is $\mathrm{M}_{6} \mathrm{C}$ carbide with a fishbone-like morphology. In the middle of the micrograph, the third phase is WC carbide with a broken needles shape.

Table 7

Calculated eutectic reactions compared to experimental measurements (see Figs. 8 and 9)

\begin{tabular}{|c|c|c|c|c|}
\hline \multirow[t]{3}{*}{ Microconstituents } & \multicolumn{4}{|c|}{ Eutectic reactions } \\
\hline & \multicolumn{2}{|c|}{ Composition (mass\%) } & \multirow[t]{2}{*}{ Calculated $T(\mathrm{~K})$} & \multirow[t]{2}{*}{ Experimental $T(\mathrm{~K}$} \\
\hline & W & $\mathrm{C}$ & & \\
\hline$\gamma / \mathrm{M}_{6} \mathrm{C} /$ cementite (metastable) & 12.7 & 3.9 & $1397^{\mathrm{b}}$ & 1358 (IV) \\
\hline$\gamma /$ WC/graphite (stable) & 5.5 & 4.2 & 1412 & $1368(\mathrm{I})$ \\
\hline$\gamma / \mathrm{M}_{6} \mathrm{C} /$ graphite (metastable) & 12.5 & 4.0 & $1392^{\mathrm{c}}$ & 1361 (III) \\
\hline
\end{tabular}

\footnotetext{
The symbols I-IV correspond to the micrographs presented in Figs. 6 and 8.

${ }^{\text {a }}$ Initially suspending the WC phase.

b Initially suspending the graphite phase.

${ }^{\mathrm{c}}$ initially suspending the WC and cementite phases.
} 

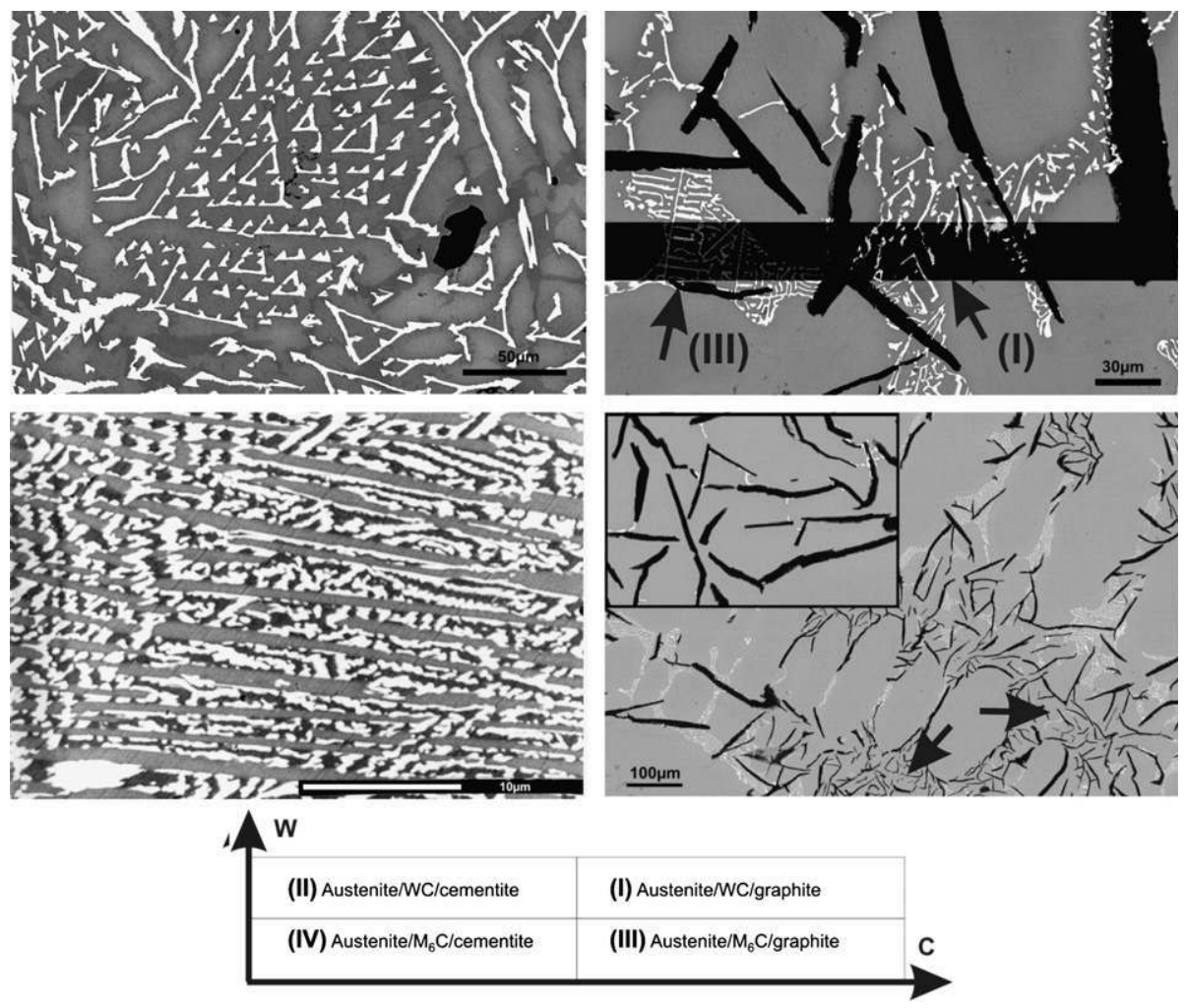

Fig. 8. Magnification of micrographs of Fig. 6 illustrating the morphologies of the four ternary eutectics formed during a solidification process. The micrographs are placed according to their $\mathrm{W}$ and $\mathrm{C}$ content respectively. For comparison, the calculated proportion of the phases in each eutectic is indicated below in molar fraction (volume fraction in brackets). Top left: eutectic (II) austenite (light grey), WC (white), cementite (dark grey). 1.3 (1.2) WC/ 50.3 (46.9) cementite. Bottom left: eutectic (IV) Austenite (dark contrast), $\mathrm{M}_{6} \mathrm{C}$ (clear contrast), cementite (grey needles). 3.8 (4.3) $\mathrm{M}_{6} \mathrm{C} / 50.7$ (47.1) cementite. Top right: eutectic (I) and (III) austenite (grey matrix), WC (white broken needles), graphite (dark flakes). 1.8 (1.7) WC/8.7 (6.8) graphite A band was taken with a very dark contrast in order to show the difference of brightness of the carbides. WC carbides in (I) appear brighter since their $\mathrm{W}$ content is higher. Bottom right: eutectic (III) austenite (grey matrix), $\mathrm{M}_{6} \mathrm{C}$ (clear contrast with fishbone shape), graphite (dark flakes). 5.5 (5.8) $\mathrm{M}_{6} \mathrm{C} / 9.2$ (7.2) graphite.

Low $W$ high $C: \gamma / M_{6}$ Clgraphite (III Fig. 8). The ternary eutectic microconstituent can be found at the interdendritic junction (arrows on the micrograph III) which is the last area to be solidified. It seems difficult to identify since the proportion of $\mathrm{M}_{6} \mathrm{C}$ is very low, which is confirmed by the calculation.

In general, it seems that in some of the earlier investigations referred to in Table 1, these types of very fine microconstituents were not detected or taken into account. In fact they can be observed only under specific conditions of enlargement and contrast. Furthermore, the eutectic carbides are not always stable at temperatures of a few tens $\mathrm{K}$ under their eutectic temperature. This may explain some of the discrepancies noted between the various investigators (Table 1). We calculated the liquidus projection. The main problem to make a correlation between the equilibrium phase diagram and our experimental findings is that most of the phases which form first are not the ones expected. The stable phases do not nucleate readily and are in this case replaced by less stable ones. To take into account these assumptions, different liquidus surfaces were drawn, suspending WC, or graphite, or WC and cementite. The results are presented in Fig. 9 in a similar way to those in Fig. 8. The ternary eutectic obtained with calculations involving all the phases liable to be found is supposed to be the stable one. This is $\gamma / \mathrm{WC} /$ graphite (Fig. 9b), which is only be observed in alloy B. However, calculations can be carried out assuming that a stable phase does not nucleate and is replaced by a less stable phase. If $\mathrm{WC}$ and cementite are suspended in the calculation (Fig. 9d), the ternary eutectic $\gamma / \mathrm{M}_{6} \mathrm{C} /$ graphite is found. If $\mathrm{WC}$ alone is suspended (Fig. 9c), the ternary eutectic $\gamma / \mathrm{M}_{6} \mathrm{C} /$ cementite is then found and its composition is close to our experimental value (Point E). If graphite is not considered in the calculations (Fig. 9a), the ternary eutectic is $\gamma / \mathrm{WC} /$ cementite.

It should be noted that if we consider the temperature of each ternary eutectic, the classification for these values is almost the same as that for experimental measurements and calculations (Table 7). However there is an overall shift of about $45 \mathrm{~K}$ between experimental and calculated temperatures. All these eutectic temperatures lie within a very narrow range of values. This may explain why so-called metastable structures are so readily obtained even in the case of slow-cooling conditions. 

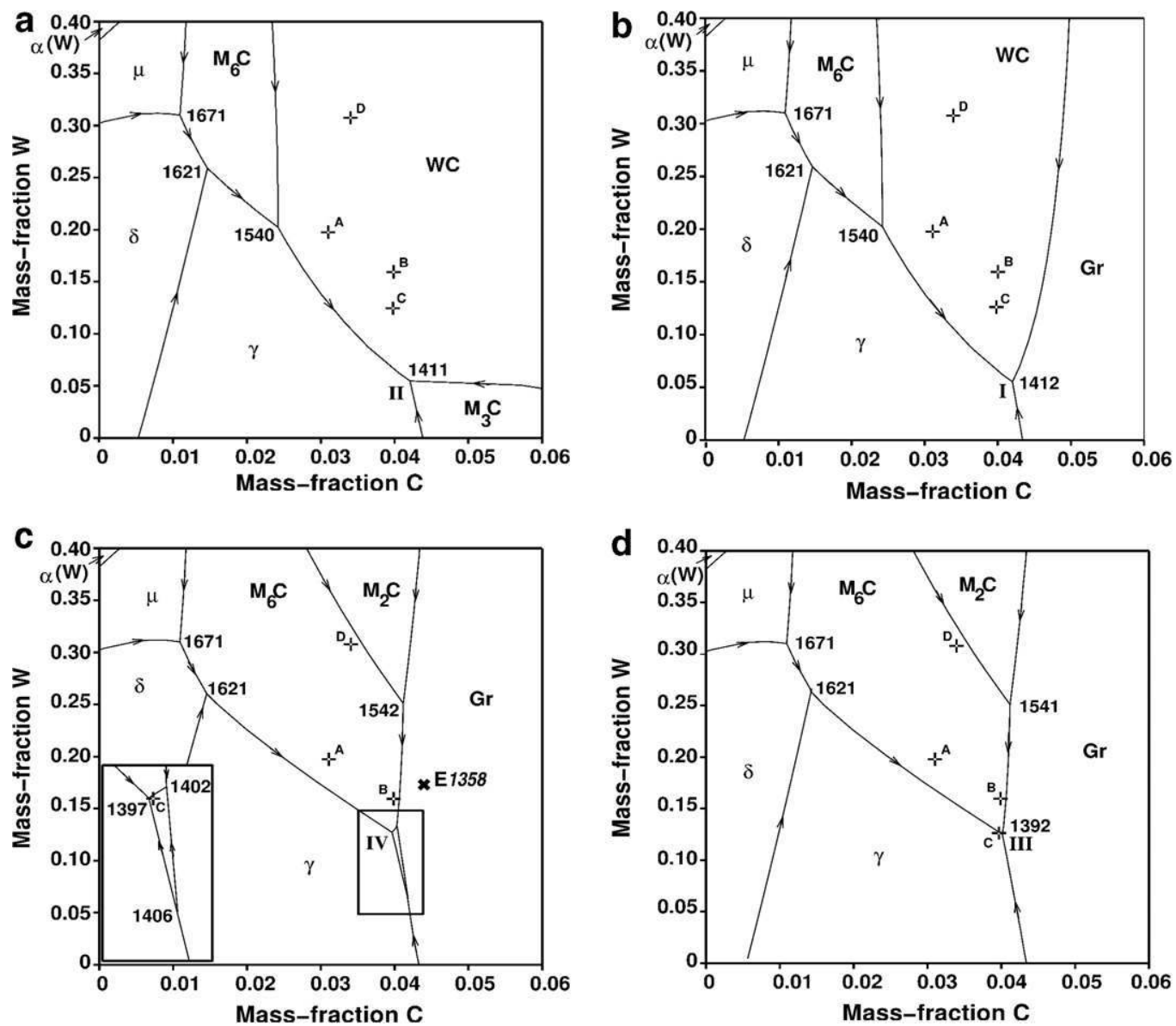

Fig. 9. Calculated projection of the liquidus surface for the Fe-W-C system, (a) excluding graphite, (b) without excluding phases, (c) excluding WC, (d) excluding WC and cementite, together with crosses marking the compositions of the investigated alloys (A-D). E represents the ternary eutectic $\gamma / \mathrm{M}_{6} \mathrm{C} /$ cementite experimentally characterised. All temperatures are given in Kelvin.

\section{Conclusion}

Our investigation was based on a careful interpretation of the microstructure obtained with different solidification conditions, taking into account the settling effect of WC carbides. Four different ternary eutectics were identified within in a narrow range of temperatures: $\gamma / \mathrm{WC} /$ cementite, $\gamma / \mathrm{M}_{6} \mathrm{C} /$ cementite, $\gamma / \mathrm{WC} /$ graphite and $\gamma / \mathrm{M}_{6} \mathrm{C} /$ graphite. Their occurrence was found to depend on the solidification rate and the composition. Equilibrium states involving the liquid phase were determined experimentally. At 1423 and $1473 \mathrm{~K}$, liq. $/ \gamma$ tie-lines and the liq./WC/ $\gamma$ tie-triangle were obtained. At $1423 \mathrm{~K}$, the liq./WC, liq./graphite, liq./ $\gamma$ tie-lines and the liq./WC/ $\gamma$ tie-triangle were determined, defining the liquid domain. At $1523 \mathrm{~K}$, the liq. $/ \mathrm{M}_{6} \mathrm{C} / \gamma$ tie-triangle was obtained. The position of the liq./WC $+\gamma$ and liq./WC $+\mathrm{M}_{6} \mathrm{C}$ monovariant lines was specified.

Concerning the formation of the four ternary eutectics, metastable calculations supplied a good basis. These experimental results suggest that this system should be reassessed by taking into account a larger $\mathrm{M}_{6} \mathrm{C}$ and $\mathrm{WC}_{1-x}$ liquidus surface. Bratberg [27] recently proposed some new data concerning the WC carbides. The integra- tion of all these new data in a new thermodynamic evaluation should allow a better description of the $\mathrm{Fe}-\mathrm{W}-\mathrm{C}$ system.

\section{References}

[1] Pollock CB, Stadelmaier H. The eta carbides in the $\mathrm{Fe}-\mathrm{W}-\mathrm{C}$ and Co-W-C systems. Met Trans A 1970;1:767-70.

[2] Uhrenius B, Harvig H. A thermodynamic evaluation of carbide solubilities in the $\mathrm{Fe}-\mathrm{Mo}-\mathrm{C}, \mathrm{Fe}-\mathrm{W}-\mathrm{C}$ and $\mathrm{Fe}-\mathrm{Mo}-\mathrm{W}-\mathrm{C}$ systems at $1000{ }^{\circ} \mathrm{C}$. Metal Sci 1975;9:67-82.

[3] Lugscheider E, Reimann H, Pankert RZ. Eta carbides in Co-W-C and Fe-W-C alloys. Z Metallkde 1982;73:321-4.

[4] Takeda S. A metallographic investigation of the ternary alloys of the iron-tungsten-carbon system. Technol Rep Tohoku Univ 1931;10: $42-92$.

[5] Jellinghaus W. Powder metallurgical contributions to the ternary systems iron-tungsten-carbon and iron-molybdenum-carbon. Arch Eisenhüttenwesen 1968;39:705-18.

[6] Shevchuk LA, Dudetskaya LR, Gurinovich VI, Tkacheva VA. Phase equilibria in the iron-carbon-tungsten alloys. Vestsi Akad Navuk BSSR, Ser Fiz-Tekh Navuk 1978;1:43-6.

[7] Gabriel A, Pastor H, Deo DM, Basu S, Allibert CH. New experimental data in the $\mathrm{C}-\mathrm{Fe}-\mathrm{W}, \mathrm{C}-\mathrm{Co}-\mathrm{W}, \mathrm{C}-\mathrm{Ni}-\mathrm{W}, \mathrm{C}-\mathrm{Fe}-\mathrm{Ni}-$ $\mathrm{W}$ and $\mathrm{C}-\mathrm{Co}-\mathrm{Ni}-\mathrm{W}$ cemented carbide systems and their application to sintering conditions. Int J Refract Hard Met 1986;5(4):215-21. 
[8] Rivlin VG. Phase equilibria in iron ternary alloys. 19: Critical review of constitution of carbon-iron-tungsten system. Int Metals Rev 1985;30(6):259-74.

[9] Shtansky DV, Inden G. Phase transformation in Fe-Mo-C and FeW-C steels. I: The structural evolution during tempering at $700{ }^{\circ} \mathrm{C}$. Acta Mater 1997;45:2861-78.

[10] Shtansky DV, Inden G. Phase transformation in $\mathrm{Fe}-\mathrm{Mo}-\mathrm{C}$ and $\mathrm{Fe}-$ W-C steels. II: Eutectoid reaction of $\mathrm{M}_{23} \mathrm{C}_{6}$ carbide decomposition during austenitization. Acta Mater 1997;45:2879-95.

[11] Hackenberg RE, Shiflet GJ. Transitions in carbide morphology in a ternary Fe-C-W steel. Met Mat Trans A 1998;29A:2087-100.

[12] Hackenberg RE, Granada DG, Shiflet GJ. Austenite decomposition to carbide-rich products in Fe-0.30C-6.3W. Met Mat Trans A 2002;33A:3619-33.

[13] Uhrenius B. Calculation of phase equilibria in the $\mathrm{Fe}-\mathrm{W}-\mathrm{C}$ system. Calphad 1980;4:173-91.

[14] Åkesson L. An experimental investigation of some phase equilibria in the Fe-W-C system. Stockholm, Sweden: Sandvik Coromant Research Center; Int Rep no 2670, 1980.

[15] Gustafson P. A thermodynamic evaluation of the C-Fe-W system. Met Trans A 1987;18:175-88.

[16] Giron G, Durand-Charre M. High temperature phase equilibria in the system Fe-Mo-C. Z. Metallkde 1995;86:15-21.

[17] Dyson DJ, Andrews KW. The structure and metallurgical significance of the iron-molybdenum carbide $\mathrm{Fe}_{2} \mathrm{MoC}\left(\mathrm{M}_{\mathrm{a}} \mathrm{C}_{\mathrm{b}}\right)$. J Iron Steel Inst. 1964;202:325-9.
[18] Shen JY, Giron G, Jay P, Durand-Charre M. Solid-liquid equilibria in the $\mathrm{Fe}-\mathrm{Mo}-\mathrm{C}$ and $\mathrm{Fe}-\mathrm{W}-\mathrm{C}$ systems. In: XXVIIIe JEEP conf, Paris, France: 1992.

[19] Durand-Charre M. Microstructure of steels and cast-irons. Springer; 2004.

[20] Allibert C, Wicker A, Driole J, Bonnier E. Détermination de diagrammes de phases à haute température dans les systémes de métaux réfractaires. Rev Int Hautes Tempér et Réfract 1970;7: $45-50$.

[21] Allibert C, Wicker A, Driole J, Bonnier E. Study of niobium based refractory metal alloys. Rev Phys Appl 1970;5:449-53.

[22] Sundman B, Jansson B, Andersson JO. The Thermo-Calc databank system. Calphad 1985;9(2):153-90.

[23] TCFE5: TCS Steels/Fe-Alloys Database version 5.0. Thermo-Calc Software AB, Stockholm, Sweden: 2005.

[24] Jonsson S. Phase relations in quaternary hard materials. Ph.D. Thesis, Royal Institute of Technology, Stockholm, Sweden: 1993.

[25] Åkesson L. Stockholm, Sweden: Sandvik Coromant Research Center; unpublished research,1983, quoted by Ref. 4.

[26] Holleck H. Binäre und ternäre Carbide und Nitride der Übergangsmetalle und ihre Phasenbeziehungen. Kernforschungszentrum: Karlsruhe; 1981.

[27] Bratberg J. Phase equilibria and thermodynamic properties of highalloy tool steels. Ph.D. Thesis, Royal Institute of Technology, Stockholm, Sweden: 2005. 